\title{
Wood formation and tree adaptation to climate
}

\section{Cyrille B. K. Rathgeber ${ }^{1}$ (D) Patrick Fonti ${ }^{2} \cdot$ Vladimir V. Shishov $^{3,4} \cdot$ Philippe Rozenberg $^{5}$}

Received: 4 October 2019 / Accepted: 18 November 2019 / Published online: 11 December 2019

(C) INRA and Springer-Verlag France SAS, part of Springer Nature 2019

\begin{abstract}
- Key message This special issue of Annals of Forest Science compiles ten papers on "Wood formation and tree adaptation to climate", which were presented at "Le Studium" International Conference in May 2018 in Orléans (France). These papers present observational, experimental and modelling studies investigating the influence of climatic changes on tree growth from the hour to the century, and from the cell to the landscape.
\end{abstract}

Keywords Tree ring $\cdot$ Xylem anatomy $\cdot$ Wood formation dynamics $\cdot$ Stem radial growth $\cdot$ Climatic changes

Tree rings are an extremely valuable source of environmental information. Tree rings have been successfully used to date anthropogenic activities, reconstruct past climates, study the dynamics of forest growth and succession, reconstruct natural disturbances and geomorphic processes and even used to quantify the contribution of the vegetation to the global carbon and water biochemical cycles. More recently, thanks to novel high-resolution tree-rings proxy and intra-annual density, anatomy or isotopes profiles, tree-ring have also served to assess the impact of climate change on tree physiology and health as well as on forest functioning and distribution or even to quantify the contribution of the vegetation to the global carbon and water cycles. Indeed, woody plants, via the formation of annual rings of xylem, not only provide a crucial natural material that fixes atmospheric $\mathrm{CO}_{2}$ contributing to

Handling Editor: Erwin Dreyer

Contribution of the co-authors C.B.K.R wrote the paper with the help of PF, VVS and PR.

This article is part of the topical collection on Wood formation and tree adaptation to climate

Cyrille B. K. Rathgeber

cyrille.rathgeber@inra.fr

Patrick Fonti

patrick.fonti@wsl.ch

Vladimir V. Shishov

vlad.shishov@gmail.com

Philippe Rozenberg

philippe.rozenberg@inra.fr mitigate climate warming, but also records and archives with intra-annual resolution, their physiological, compositional and structural responses to changing developmental and environmental conditions.

Wood provides four essential functions in trees, namely it (1) supports and spatially distributes the photosynthetic tissues above ground; (2) conducts the raw sap (i.e. water and nutrients) from the roots up to the leaves; (3) stores carbohydrates, water and other compounds; and finally (4) protects the trees from pathogens, by storing and distributing defensive compounds. The ability of trees to face environmental stress, including climate change, strongly depends on wood capacity to provide these vital functions. Generally, the anatomy, structure and functions of the wood fit the environmental conditions trees are living in. However, under a strongly and rapidly

1 Université de Lorraine, AgroParisTech, INRA, Silva, F-54000 Nancy, France

2 Swiss Federal Institute for Forest, Snow and Landscape Research WSL, Zürcherstrasse 111, 8903 Birmensdorf, Switzerland

3 Mathematical Methods and Information Technology Department, Siberian Federal University, L Prushinskoi st., 2, 660075 Krasnoyarsk, Russia

4 Le Studium Loire Valley Institute for Advanced Studies, 1 rue Dupanloup, 45000 Orléans, France

5 UMR 588 BIOFORA, INRA, F-45075 Cedex 2, Orléans, France 
changing climate, these characteristics need adjustments that might lie outside the current natural phenotypic plasticity and/ or evolutionary adaptation of trees. A more detailed mechanistic understanding of the process leading to wood formation is therefore crucial to fully exploit this wonderful natural archive. Questions such as "which environmental factor induced what feature", "when during the growing season does it occurred", "what process are involved in the creation of such a feature" are fundamental questions to link effects to causes and structures to functions.

Since observations of wood formation are hindered by the fact that growth occurs under the bark of a tree, tree-ring development must be assessed via a variety of 'indirect' methods. Techniques such as stem-dimension monitoring (dendrometers), repeated marking (pinning), and sampling (micro-coring) of the stem at regular intervals during the growing season can be used to study wood formation dynamics. Thanks to the continuous improvements in measuring tools, techniques and methods, there is an increasing capacity to explore tree rings structure at high resolutions, opening new frontiers in environmental research.

To promote a sound future management of forest resources it is thus fundamental that tree breeders and forest managers select and promote individuals, provenances and species that best fit uncertain future conditions. It is therefore important and urgent that plant scientists provide tools and knowledge helping to identify and select the most relevant adaptive traits.

This special issue of Annals of Forest Science compiles ten papers on "Wood formation and tree adaptation to climate", which were presented at the "Le Studium" International Conference (http://www.lestudium-ias.com/event/woodformation-and-tree-adaptation-climate). This conference, organized by Prof. Vladimir Shishov and Dr. Philippe Rozenberg, from the 23 to the 25 May 2018 in Orléans (France), gathered 72 researchers from 18 countries and five continents-Asia (1), Europe (51), North America (15), South America (4), and Australia and Oceania (1).

This special issue includes timely contributions from observational, experimental and modelling studies in the broad field of tree-ring sciences. Some large-scale observational studies based on tree-ring width and structure are dealing with global change impacts on forest and fire dynamics (Abrams and Nowacki 2019), as well as on permafrost and wood quality (Arzac et al. 2019). More detailed observational studies focus on the adaptive response of trees to rapidly changing environments, in terms of stem cycle variations (Balducci et al. 2019), wood formation phenology (Saderi et al. 2019) and dynamics (Nanayakkara et al. 2019), intra-annual dynamics of carbon sequestration (Andrianantenaina et al. 2019), and resulting tree-ring structure and function (Rosner et al. 2019). Moreover, experimental studies explore the impact of forecasted climate changes (global warming and drought events in particular) on primary and secondary growth (Vieira et al. 2019), as well as on tree mortality, in interaction with biotic stress such as defoliation (Bouzidi et al. 2019). Finally, an opinion paper (Friend et al. 2019) shows how a mechanistic understanding of wood formation process may not only serve tree-ring sciences, but also help developing more realistic global dynamic vegetation models to confidently assess the carbon cycle.

Acknowledgements The authors wish to thank the contributors of this special issue for their dedicated work.

Data availability statement Data sharing not applicable to this article as no datasets were generated or analysed during the current study.

Funding This work is supported by a grant overseen by the French National Research Agency (ANR) as part of the "Investissements d'Avenir" program (ANR-11-LABX-0002-01, Lab of Excellence ARBRE).

\section{Compliance with ethical standards}

Conflict of interest The authors declare that they have no conflict of interest.

\section{References}

Abrams MD, Nowacki GJ (2019) Global change impacts on forest and fire dynamics using paleoecology and tree census data for eastern North America. Ann For Sci 76:1-23. https://doi.org/10.1007/ s13595-018-0790-y

Andrianantenaina AN, Rathgeber CBK, Pérez-de-Lis G, Cuny H, Ruelle J (2019) Quantifying intra-annual dynamics of carbon sequestration in the forming wood: a novel histologic approach. Ann For Sci 76: 1-12. https://doi.org/10.1007/s13595-019-0846-7

Arzac A, Popkova M, Anarbekova A, et al (2019) Increasing radial and latewood growth rates of Larix cajanderi Mayr. and Pinus sylvestris L. in the continuous permafrost zone in Central Yakutia (Russia). Ann For Sci

Balducci L, Deslauriers A, Rossi S, Giovannelli A (2019) Stem cycle analyses help decipher the nonlinear response of trees to concurrent warming and drought. Ann For Sci 76:1-18. https://doi.org/10. 1007/s13595-019-0870-7

Bouzidi HA, Balducci L, Mackay J, Deslauriers A (2019) Interactive effects of defoliation and water deficit on growth, water status, and mortality of black spruce (Picea mariana (Mill.) B.S.P.). Ann For Sci 76. https://doi.org/10.1007/s13595-019-0809-Z

Friend AD, Eckes-Shephard AH, Fonti P, Rademacher TT, Rathgeber CBK, Richardson AD, Turton RH (2019) On the need to consider wood formation processes in global vegetation models and a suggested approach. Ann For Sci 76:76-13. https://doi.org/10.1007/ s13595-019-0819-x

Nanayakkara B, Dickson AR, Meason DF (2019) Xylogenesis of Pinus radiata D. Don growing in New Zealand. Ann For Sci 76:1-11. https://doi.org/10.1007/s13595-019-0859-2

Rosner S, Johnson DM, Voggeneder K, Domec J-C (2019) The conifercurve: fast prediction of hydraulic conductivity loss and 
vulnerability to cavitation. Ann For Sci 76:1-15. https://doi.org/10. 1007/s13595-019-0868-1

Saderi S, Rathgeber CBK, Rozenberg P, Fournier M (2019) Phenology of wood formation in larch (Larix decidua Mill.) trees growing along a $1000-\mathrm{m}$ elevation gradient in the French Southern Alps. Ann For Sci 76:1-17. https://doi.org/ 10.1007/s13595-019-0866-3
Vieira J, Moura M, Nabais C, Freitas H, Campelo F (2019) Seasonal adjustment of primary and secondary growth in maritime pine under simulated climatic changes. Ann For Sci 76:76-12. https://doi.org/ 10.1007/s13595-019-0865-4

Publisher's note Springer Nature remains neutral with regard to jurisdictional claims in published maps and institutional affiliations. 